\title{
Editorial
}

\section{ARE YOU LOSING YOUR HEAD IN FOOTBALL?}

The recognition of chronic traumatic encephalopathy (CTE) exposed the vested interests of the National Football League (NFL) in the United States, in attempting to keep the effects of repetitive concussions in the game of football (American football involves direct head trauma and bone jarring tackles) under cover. CTE's earliest diagnosis was made posthumously in 2005 on Pittsburgh Steeler center 'Iron Mike', Webster who had died of a heart attack in 2002. ${ }^{1}$ Despite initial denials of CTE by the NFL voiced by about 16 papers in the Journal Neurosurgery, growing body of evidence has emerged which has led to recognition of concussions as well as change in the rules of the game. ${ }^{2,3}$ A provocative question remains - whether concussion due to football or other contact games entails a risk of development of degenerative disease?

Neurotrauma as a direct consequence of road traffic accidents has also resulted from an exponential increase in number of vehicles on the road. India has $<1 \%$ of total vehicles in the world, but accounts for $>6 \%$ of road accidents. With the Indian accident rate 35/1000 vehicles, it is probably the highest in the world. With bigger and faster cars emerging on the Indian highways, high-energy impact of these accidents leads on to disabling injuries, which are proportionately getting harder to treat. ${ }^{4}$ Neurotrauma itself carries a high rate of morbidity and mortality. This issue needs attention of all the health communities. According to the WHO, Violence and Injury Prevention and Disability (VIP), these injuries cause enormous losses to individuals, families and communities. They result in a large number of deaths and impairments leading to permanent disabilities. For the same reason, we need to set-up surveillance teams and projects to counter this issue. Traumatic brain injury may lead to diffuse axonal injury associated poor long-term outcomes. Enhanced public participation and awareness programs are needed. With the advent of the New Year, we all should take a moment and set the pace to find ways of promoting safer road travel.

\section{REFERENCES}

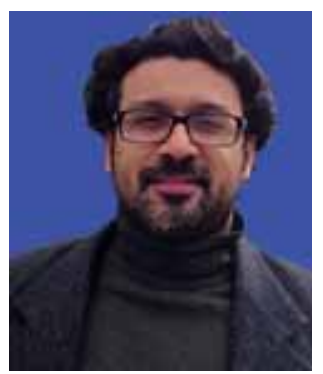

Dheeraj Khurana

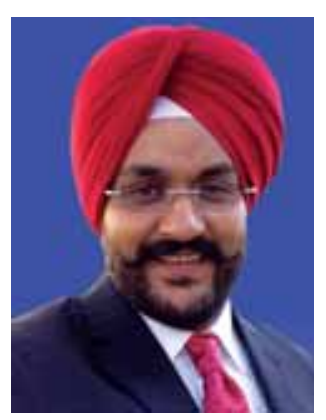

Sarvdeep S Dhatt

1. Omalu BI, DeKosky ST, Minster RL, Kamboh MI, Hamilton RL, Wecht CH. Chronic traumatic encephalopathy in a National Football League player. Neurosurgery 2005;57:128-134.

2. AAN sports concussion toolkit/resources. Available at: www.aan.com/concussion

3. NFL safety rules. Available at: http:bit.ly/1bhh7Wr

4. Stelfox HT, Joshipura M, Chadbunchachai W, Ellawala RN, O’Reilly G, Nguyen TS, Gruen RL. Trauma quality improvement in low and middle income countries of the Asia-Pacific region: a mixed methods study. World J Surg 2012 Aug;36(8):1978-1992.

\author{
Dheeraj Khurana \\ Additional Professor, Department of Neurology \\ Postgraduate Institute of Medical Education \\ and Research, Chandigarh, India \\ Sarvdeep S Dhatt \\ Assistant Professor, Department of Orthopedics \\ Postgraduate Institute of Medical Education \\ and Research, Chandigarh, India
}

